\title{
Schmidt und Schorm zum neuen KZV-Vorstand gewählt
}

Die Vertreterversammlung (VV) der Kassenzahnärztlichen Vereinigung (KZV) Sachsen-Anhalt hat sich am 2. Januar 2017 in Magdeburg neu konstituiert und den Vorstand der KZV für die Legislaturperiode 2017 bis 2022 gewählt. Einstimmig wurde Dr. Jochen Schmidt aus Dessau-Roßlau zum neuen Vorstandsvorsitzenden und Dr. Stefan Schorm aus Bitterfeld-Wolfen zum Stellvertreter des Vorstandsvorsitzenden gewählt. Damit ist der Freie Verband Deutscher Zahnärzte (FVDZ) stark vertreten.

Dr. Jochen Schmidt ist in dritter Generation Zahnarzt. Der 54-Jährige setzt sich bereits seit mehr als 25 Jahren in verschiedensten Positionen ehrenamtlich für die Belange der Zahnärzte in Sachsen-Anhalt und auf Bundesebene ein. Er war langjähriger Landesvorsitzender des Freien Verbandes in Sachsen-Anhalt und ist aktuell unter anderem auch Delegierter in der Kammerversammlung der Zahnärztekammer Sachsen-Anhalt.

Dr. Stefan Schorm (50) ist Gründer einer Praxis in Sandersdorf (Landkreis Anhalt-Bitterfeld), die inzwischen Teil einer Berufsausübungsgemeinschaft (BAG) ist. Auch er ist Mitglied im FVDZ und sammelte bereits Erfahrungen in den Gremien der Vertragszahnärzteschaft und als Mitglied der KZV-Vertreterversammlung von 2005 bis 2010 .

„Wir freuen uns über das gute Ergebnis und das uns entgegengebrachte Vertrauen. Unser Ziel ist es, die freiberufliche Basis der zahnärztlichen Berufsausübung und die Selbstverwaltung zu stärken“, so Dr. Schmidt.

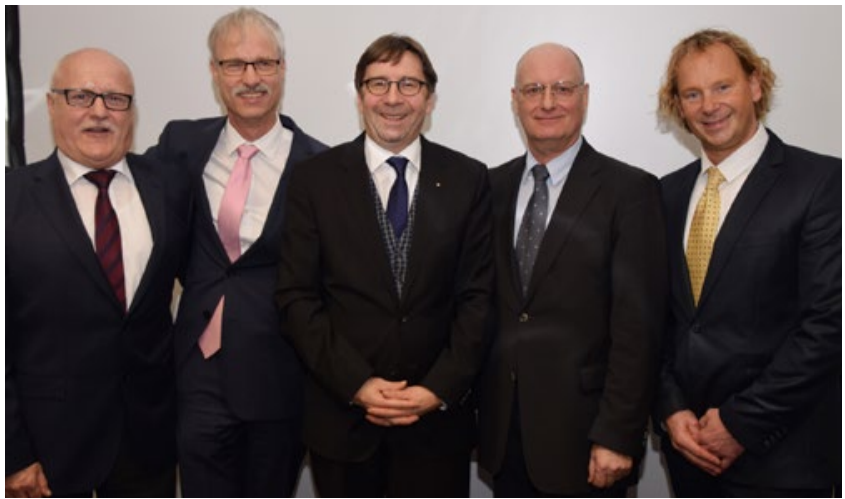

VV-Vorsitzender Dr. Bernd Hübenthal, Vorstandsvorsitzender Dr. Jochen Schmidt, FVDZ-Landesvorsitzender und KZV-Pressereferent Matthias Tamm, stellv. VV-Vorsitzender Dr. Hans-JörgWiller und stellv. Vorstandsvorsitzender Dr. Stefan Schorm (v. li.)

Hier steht eine Anzeige. 